\title{
Monetary and Fiscal Policy in the Presence of Informal Labour Markets: A DSGE Approach
}

\author{
Omobola Adu ${ }^{1}$, Philip Alege ${ }^{1} \&$ Oluranti Olurinola ${ }^{1}$ \\ ${ }^{1}$ Covenant University, Nigeria \\ Correspondence: Omobola Adu, Covenant University, Nigeria.
}

Received: June 21, 2020

doi:10.5430/rwe.v12n1p213
Accepted: July 31, 2020

Online Published: January 6, 2021

URL: https://doi.org/10.5430/rwe.v12n1p213

\begin{abstract}
In this paper, we investigate the transmission mechanism of monetary and fiscal policy shocks on inflation and output in the presence of an informal economy in Nigeria. To achieve this, a New Keynesian Dynamic Stochastic General Equilibrium (DSGE) model is modified to include informality in the labour and product market. The model is estimated using the Bayesian technique and the findings shows that in the case of a monetary policy shock, formal output tends to decline, while there is an expansion in informal output, at least in the short-run. The results also reveal that a fiscal policy shock brings about an initial decline in informal output. Hence, it is imperative for policymakers to strive to formalise the informal sector in order to ensure the effectiveness of monetary policy.
\end{abstract}

Keywords: informal economy, DSGE, bayesian estimation

\section{Introduction}

Monetary and fiscal policy is generally regarded as the major tools of macroeconomic management. This is because at least in the short-run, changes in the policy rate of the central bank are able to influence macroeconomic aggregates like inflation and output. Furthermore, key fiscal policy decisions of the government are able to impact nominal variables like the interest rate (Oye, Alege and Olomola, 2018). As a result of the impact of monetary and fiscal policy on macroeconomic aggregates, several studies have investigated how the policy objectives of central banks should be designed (CBN, 2013; Ahmed, Khan and Rehman, 2013).

The New Keynesian models, particularly the Dynamic Stochastic General Equilibrium (DSGE) models have largely become instrumental for researchers and policymakers towards analysing the likely impact of policy actions on the economy. Ahmed et al., (2012) asserts that DSGE models have become the workhorse for central banks. In Nigeria, a number of studies have attempted to use these models to understand the transmission mechanism of monetary policy on the Nigerian economy (Alege, 2012; CBN, 2013; Oye, Alege and Olomola, 2018). However, majority of these studies ignored the presence of labour market frictions, which is crucial for a developing economy like Nigeria.

The Nigerian economy is characterised by a large informal economy estimated to account for over 90 percent of total employment in the country (SMEDAN and NBS, 2019). According to NBS (2016), in 2015, the informal sector was acknowledged to contribute about 41.43 percent to Nigeria's Gross Domestic Output (GDP). Hence, based on these statistics, it implies that policy decisions based on official statistics might be rendered ineffective because of the exclusion of the informal economy. Kolev and Morales (2005) opine that because the informal economy is largely unobservable, it is likely that for developing countries, the desired effect of policies is seen in the formal sector, but the overall economy is worse-off due to the existence of a larger share of the informal economy.

Therefore, given the large size of the Nigerian informal economy, it is crucial that the design of macroeconomic models addressing the transmission mechanism of monetary and fiscal policy should consider how the presence of a dual labour market is likely to affect inflation and output dynamics. Consequently, the major objective of this study is to understand how the impacts of monetary and fiscal shocks are transmitted on macroeconomic aggregates, in particular, output and inflation, in the presence of informal labour markets.

To the best of the researchers' knowledge, this is the first study to attempt to model the behaviour of the informal economy in a macroeconomic model for Nigeria using a DSGE model. Existing DSGE studies for Nigeria, such as CBN (2013) and Oye, Alege and Olomola (2018) did not take into consideration the presence of dual labour markets. We introduce informality in a simple DSGE model in the labour and product market to understand how its presence 
affects monetary and fiscal policy shocks. The remainder of this paper is organised as follows: Section 2 provides a review of the empirical literature modelling the informal economy; the stylised facts on monetary and fiscal policy decisions in Nigeria are presented in Section 3; The DSGE model of the study is provided in Section 4, while the empirical results are discussed in Section 5. The conclusions of the study are provided in Section 6.

\section{Literature Review}

This section of the study provides an empirical review of DSGE studies incorporating an informal sector. Restrepo-Echavarria (2014) developed a business cycle model with two sectors. The essence of the two sectors was to reflect the presence of a formal and an informal sector towards exploring the effect informality has on macroeconomic fluctuations. The paper argues that a high degree of informality is evidenced by a substantial volatility of consumption much larger than the volatility of output because agents in the economy respond to real shocks by substituting formal for informal consumption over the business cycle. Using data for Spain, Austria, South Africa and Philippines, the results showed that a productivity shock to the informal sector causes the household to move labour from the formal to the informal sector, thereby exchanging formal consumption for informal consumption leading to higher output in the informal sector.

Castillo and Montoro (2010) presented a DSGE model towards investigating how changes in the informal labour markets influences the price level and the transmission mechanism of both supply shocks and demand shocks. The DSGE model included a two-sector labour market with the prevalence of formal and informal labour contracts. Labour market frictions in the context of hiring costs generated by the rate of flow of employment from the formal to the underground sector which was identified as labour market tightness. The empirical findings showed that the presence of informality induced a shock absorbing role in the advent of productivity and demand shocks. In particular, aggregate demand shocks to the economy induced inflation to respond by almost 42 percent larger with only the formal labour market presence. The major finding of the paper was that the inflation dynamics depends not just on unemployment, but also on the flow of workers from the formal sector to the underground sector. However, the model did not account for the role of government policy, such as government spending in affecting the dynamics of inflation.

Junior Garcia-Cintado and Usabiaga (2017) employed a DSGE model to explore the fiscal adjustments and the informal economy. The results show that expenditure-based fiscal consolidations in an economy with an active underground sector are effective in achieving public debt sustainability and even if there would be any negative impact, it would be a mild recession. However, when calibrations were used to lower the number of informal employments in the model, it was observed that reducing government spending does not prompt an improvement in the fiscal operations of the economy. On the contrary, for the economy of Brazil that has a large informal sector, any alteration in taxation will worsen both fiscal collection and public debt. However, due to the capacity of the informal economy to act as a buffer, the effect might not necessarily result in a recession. In industrialized economies with a lower rate of the informal sector, changes in taxation would not affect public debt sustainability. The study concludes that in economies like Brazil with a large underground sector, the increasing tax rate would not influence the fiscal operation of a country positively. Instead, expenditure-cutting could put the fiscal aspect of a country in order.

In order to determine how informal economic activities affect the coordination of monetary and fiscal policy, Bandaogo (2016) makes uses of DSGE to achieve this objective. Informal economic activities are defined as activities outside the control of government authorities. The model was calibrated using data for Morocco. The major finding of the paper is that the existence of an informal sector significantly diminishes the optimal tax rate imposed on the formal sector. In addition, optimal exchange rate policy is one that has an exchange rate peg in combination with a flat tax rate in comparison to a discretionary exchange rate rule. As suggested by the study, the study can be extended or adjusted by the relaxation of the assumption that government authorities do not run into budget deficit. This will provide robust findings as most African countries are characterised by large budget deficits.

In South Africa, Munkacsi and Saxegaard (2017) explored how the labour and product market influences the macroeconomy in the absence of governmental interference in both markets. The study estimated a small open DSGE model utilising the Bayesian method and the overall result indicated that the underground sector is crucial in determining the magnitude of the response of a deregulation shock on the economy. Furthermore, the results revealed that a reform in the labour and product market substantially increases output. In addition, the findings revealed that unemployment was drastically reduced by the reforms in the labour market. However, the study also noted that the deregulation shock could also lead to some adverse effect on the economy in the short term, in the form of a decline in household spending, output, net exports and competition. The authors noted that these short-term costs caused by the labour market reforms can be reduced by combining it with the reforms in the product market. 
With the need to have a standard macro-econometric model for policy analysis, CBN (2013) constructed a three sector DSGE model featuring a household sector, firms and a monetary authority using quarterly data. The model considered aggregate demand shock, supply shock, monetary policy shock, oil price shock, external reserve shock and an exchange rate shock. Having calibrated and estimated the model, the findings indicated that both demand and supply shocks proxy by government spending and inflation, respectively led to a rise in total output and inflation. Monetary policy shocks caused interest rates to decline, thereby inducing a direct impact on output and inflation, whereas the exchange rate increased suggesting the persistence of imports. Oil price shocks induced positive response on the macroeconomic aggregates. The study was able to examine the impact of both real and nominal variables on the Nigerian economy. However, the model did not incorporate the fiscal authority and an informal sector which are crucial elements for the Nigerian economy.

\section{Stylised Facts on Monetary and Fiscal Policy in Nigeria}

\subsection{Trend Analysis on Monetary Policy Stance}

\subsubsection{The Monetary Policy Stance of the CBN Has Been Tighter Than Loose From 2006 to 2017}

Figure 1 shows that using the MPR as the central policy instrument, the monetary policy stance of the CBN has been more tight than loose or neutral from 2006 to 2017 (CBN, 2017). During this period, the MPR was increased five times (2007 to 2008; 2009 to 2010; 2010 to 2011; 2013 to 2014; and 2015 to 2016). The tight monetary policy stance of the CBN was more evident from 2009 to 2011 as the MPR was increased twice. The increase in the MPR was to mop out the excess liquidity in the economy as a result of the loose monetary policy stance the CBN adopted during the global financial and economic downturn. During the economic crisis, the MPR declined by 350 basis point to 6 percent in 2009 from 9.50 percent in 2007 in order to build up liquidity shortages in the banking sector. This allowed the money supply to more than double as it rose from $\$ 5.12$ trillion in 2007 to $\$ 10.78$ trillion in 2009. Following a re-emergence of liquidity in the banking sector, the MPR was gradually increased from 6 percent in 2009 to 6.25 percent in 2010 and then there was a rapid increase by 575 basis points in 2011 as the MPR rose to 12 percent.

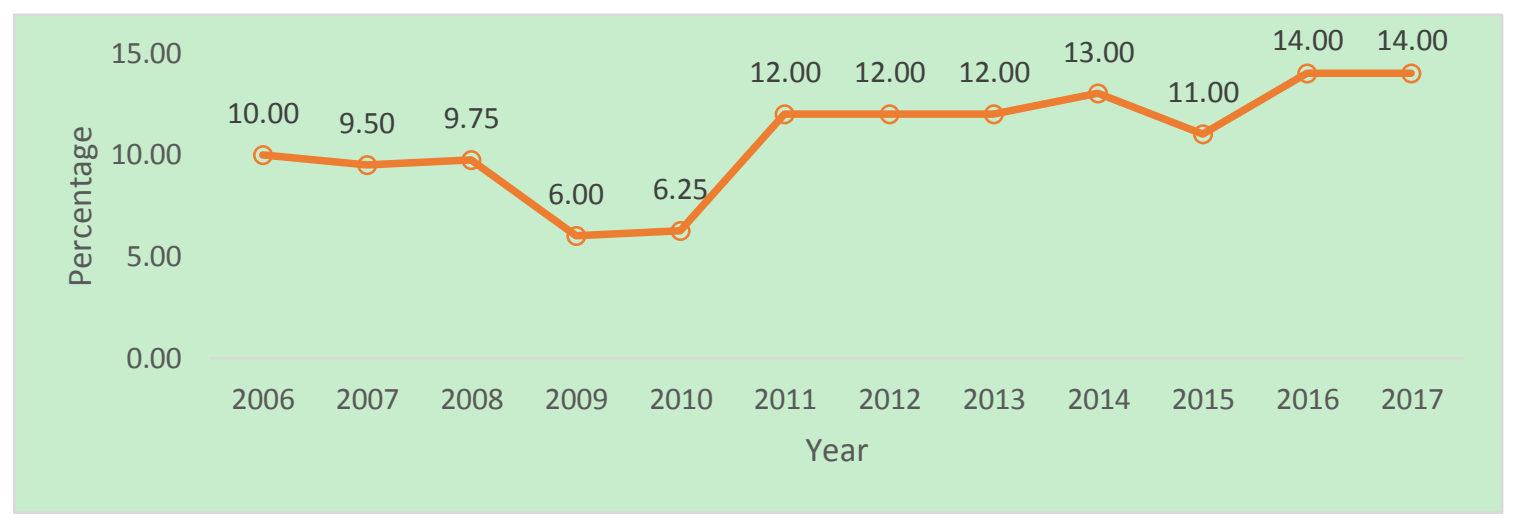

Figure 1. Monetary policy stance of the CBN (2006 to 2017)

Source: Researcher's computation from CBN (2017)

\subsection{Trend Analysis on Fiscal Policy in Nigeria}

\subsubsection{The Budgetary Stance of Fiscal Policy in Nigeria Is Largely Deficit Budgeting}

The Fiscal balance as a percentage of GDP is shown in Figure 2 and further reflects the deficit budgeting stance and expansionary fiscal policy in Nigeria. The graph shows that since 2001, Nigeria has been able to meet the convergence criteria of having a fiscal deficit to GDP ratio of below 3 percent. The fiscal deficit to GDP ratio in Nigeria has averaged -1.53 percent from 2001 to 2017. Although, in 2017, the ratio marginally exceeded 3 percent recording -3.23 percent. 


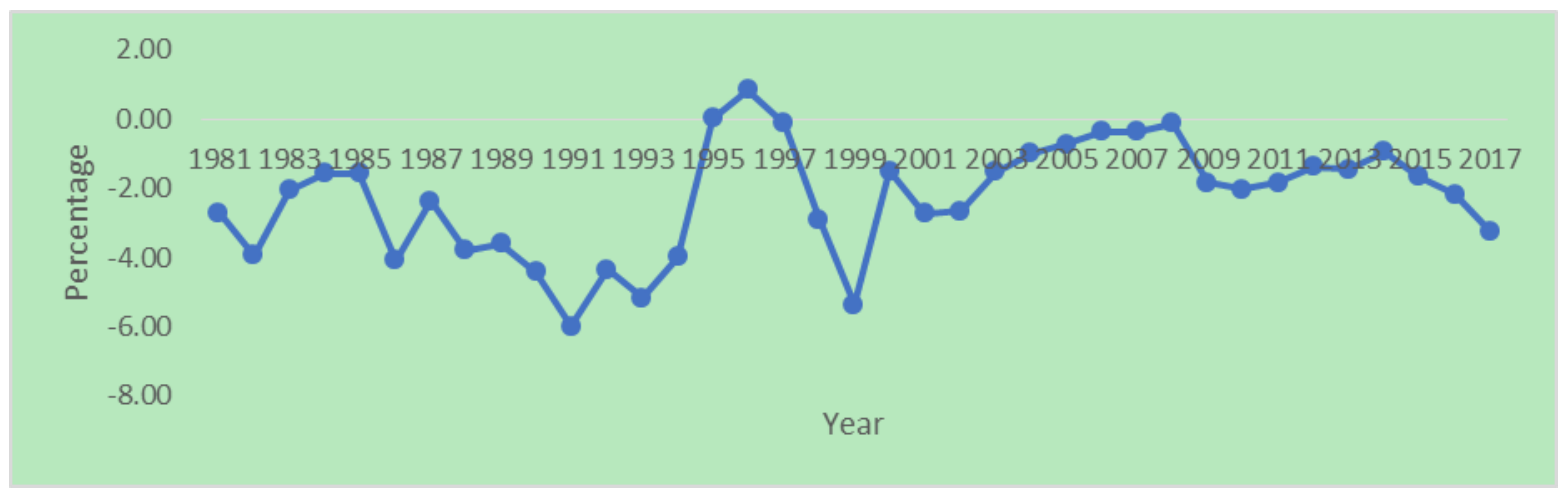

Figure 2. Fiscal balance as a percentage of GDP in Nigeria

Source: Researcher's computation from CBN (2017)

\section{Methodology}

There are four economic agents in the DSGE model of this study, namely: household, firm, fiscal agent and the monetary agent. The study introduces a dual labour market: formal and informal labour market, where the household supplies labour to either market. The firms are decomposed into formal firm and an informal firm. The monetary agent is assumed to follow the Taylor rule principle, and the fiscal agent is guided by an expenditure and taxation rule.

\subsection{Household}

The model comprises of a representative household that derives utility from leisure and the consumption of goods and services. This utility function is given as follows:

$$
U\left(C_{t}, H_{t}\right)=E_{t} \sum_{t=0}^{\infty} \beta^{t}\left[U\left(\bar{C}_{t}, 1-H_{t}\right)\right]
$$

Equation (1) describes the inter-temporal utility function of the household where $\beta^{t}$ is a discount factor denoting the consumption choice overtime, $\bar{C}_{t}$ indicates the consumption of goods by the household and $1-H_{t}$ is used to reflect leisure. Equation (1) can be expanded further as:

$$
U\left(C_{t}, H_{t}\right)=E_{t} \sum_{t=0}^{\infty} \beta^{t}\left[\frac{\bar{c}_{t}^{1-\sigma}}{1-\sigma}-\frac{H_{t}^{1+\theta}}{1+\theta}\right]
$$

In Equation (2), the inverse elasticity of substitution of consumption is captured by the parameter $\sigma$ and $\theta$ is the parameter expressing the inverse elasticity of labour supply.

The consumption bundle of the household $\left(C_{t}\right)$ is divided between goods produced in the formal sector $\left(C_{F, t}\right)$ and informal goods $\left(C_{I, t}\right)$. This consumption bundle between formal and informal goods of the household is guided by Dixit and Stiglitz (1997) constant elasticity of substitution (CES) index given as follows:

$$
C_{t}=\left[(1-\chi)^{\frac{1}{\beta}} C_{F, t}^{\frac{\beta-1}{\beta}}+(\chi)^{\frac{1}{\beta}} C_{I, t}^{\frac{\beta-1}{\beta}}\right]^{\frac{\beta}{\beta-1}}
$$

The share of formal goods in the consumption bundle is defined by $(1-\chi)$, while informal good's share is denoted by $(\chi)$. The parameter $(\beta)$ is used to reflect the elasticity of substitution between the formal and informal goods. In making consumption and labour decisions, the household is guided by a budget constraint defined as:

$$
P_{t} C_{t}+P_{t} I_{t}+E_{t}\left(Q_{t, t+1} B_{t+1}\right) \leq W_{t} H_{t}+r_{t}^{k} K_{t}+\Pi_{t}+D_{t}+T P_{t}
$$

The right-hand side of Equation (4) represents the earnings of the household: $W_{t} H_{t}$ denotes wages, $r_{t}^{k} K_{t}$ indicates capital returns, $\Pi_{t}$ denotes return on investment, $D_{t}$ captures returns from bond holdings and $T P_{t}$ reflects transfer payments from the government. The left-hand side denotes the expenditure of the household.

Hence, the objective of the household is to maximise the utility function (Equation 2) subject to the budget constraint (Equation 4). The first-order conditions derived from maximisation problem of the household leads to: 


$$
\begin{gathered}
1=\beta R_{t} \mathrm{E}_{t}\left[\frac{\left(\bar{C}_{t+1}\right)^{-\sigma}}{\left(\bar{C}_{t}\right)^{-\sigma}}\right] \frac{P_{t}}{P_{t+1}} \\
\frac{W_{t}}{P_{t}}=\frac{H_{t}^{\theta}}{\left(\bar{C}_{t}\right)^{-\sigma}} \\
E_{t}\left[\frac{\pi_{t+1}}{\left(1+R_{t}\right)}\left\{(1-\delta)+r_{t+1}^{k}\right\}\right]=1
\end{gathered}
$$

The Euler equation for consumption is represented by Equation (5), while Equation (6) represents the marginal rate of substitution between consumption and labour, and Equation (7) defines the real rate of return between bonds and capital.

\subsection{The Household's Labour Supply Choice}

The aggregate labour supply decision $\left(H_{t}\right)$ is expressed in the form of a CES index decomposed into formal labour, $H_{t}^{F}$, and informal labour, $H_{t}^{I}$.

$$
H_{t}=\left[\psi^{-\kappa}\left(H_{t}^{F}\right)^{1+\varphi}+(1-\psi)^{-\kappa}\left(H_{t}^{I}\right)^{1+\varphi}\right]^{\frac{1}{1+\varphi}}
$$

Equation (8) shows that a fraction of the household $(\psi)$ supplies labour services to formal firms, while the remainder $(1-\psi)$, provides labour to the informal firms.

\subsubsection{Firms}

As earlier mentioned, the production sector of the economy is categorised into two types of firms, the formal and informal firms. This sub-section provides the description of the behaviour of both firms.

\subsubsection{Formal Firms}

The formal firm is assumed as a monopolistic competitive firm making use of labour and capital in the production of goods. Following Ahmed, et al. (2012), the production function is guided by a constant return to scale function expressed as:

$$
Y_{F, t}=A_{t} H_{F, t}^{1-\alpha} K_{t}^{\alpha}
$$

Where the labour and capital factor inputs of the firm are defined as $H_{F, t}$ and $K_{t}$, respectively. $A_{t}$ in Equation (9) denotes an exogenous level of productivity which is assumed to follow an autoregressive process, such that in its log-linearised form, it can be defined as follows:

$$
a_{t}=\rho_{a} a_{t-1}+\varepsilon_{F, t}^{a}
$$

The formal firm proceeds on a two-stage optimisation process. Stage one involves minimising the cost function of the firm (labour and capital) in order to produce a particular output level. In real terms, the cost function of the firm is given as:

$$
C T_{t}=w_{F, t} h_{F, t}+r_{t}^{k} k_{t}
$$

The first-order conditions for labour and capital when combined from the solution of the minimisation problem yields:

$$
\frac{r_{t}^{k}}{w_{F, t}}=\frac{\alpha}{1-\alpha}\left(\frac{H_{F, t}}{K_{t}}\right)
$$

The real marginal cost of the formal firm is defined as follows:

$$
m c_{F, t}=\frac{1}{a_{t}}(\alpha)^{-\alpha}(1-\alpha)^{-(1-\alpha)}\left(w_{F, t}\right)^{1-\alpha}\left(r_{t}^{k}\right)^{\alpha}
$$

Stage two of the optimisation process of the formal firm has to do with price setting. The price setting process follows Calvo (1983) regime, where at a particular period of time, only a fraction of formal firms $\left(1-\theta_{F}\right)$ set optimally new prices and the remaining share of firms keep their price unchanged. The profit maximisation process 
for a representative firm adjusting their price $\left(P_{F, t}^{*}\right)$ is derived from maximising profit (Equation 14) subject to the demand function (Equation 15).

$$
\begin{gathered}
\pi=\operatorname{Max} E_{t} \sum_{k=0}^{\infty} \theta_{T}^{k} E_{t}\left[Q_{t, t+k} Y_{F, t+k}\left(P_{F, t}^{*}-M C_{F, t+k}\right)\right] \\
Y_{F, t+k}=\left(\frac{P_{F, t}^{*}}{P_{F, t+k}}\right)^{-\varepsilon} Y_{F, t+k}
\end{gathered}
$$

\subsubsection{Informal Firms}

As opposed to the formal firm, the informal firm is modelled as a perfectly competitive firm using labour as the factor input. Hence, the production function of the informal firm is described as follows:

$$
Y_{I, t}=\zeta H_{I, t}
$$

$\zeta$ is a parameter that denotes the productivity of informal labour. The profit maximisation problem of a representative informal firm is defined in real terms as:

$$
L=w_{I, t} h_{I, t}+\lambda_{t}\left[Y_{I G, t}-\xi H_{I G, t}\right]
$$

The first-order condition with respect to labour is given as:

$$
w_{I, t}-\lambda_{t}[\xi]=0
$$

Based on Equation (18), the real marginal cost of the informal firm is defined as follows:

$$
p_{I, t}=\frac{w_{I, t}}{\xi}
$$

\subsection{Monetary Agent}

The monetary agent is defined to follow to the Taylor (1993) rule, such that the nominal interest rate is anchored towards changes inflation and output from their targets. The process is represented as follows:

$$
\frac{R_{t}}{R}=\left[\frac{R_{t-1}}{R}\right]^{\rho_{R}}\left[\left(\frac{Y_{t}}{Y}\right)^{\theta_{Y}}\left(\frac{\pi_{t}}{\pi}\right)^{\phi_{\pi}}\right]^{1-\rho_{R}} \varepsilon_{t}^{R}
$$

In Equation (20), $R_{t}, Y_{t}, \pi_{t}$ and $\varepsilon_{t}^{R}$ represents the nominal interest rate, output, inflation rate and shocks to interest rates. Log-linearising Equation (20) gives:

$$
s r_{t}=\rho_{r} r_{t-1}+\left(1-\rho_{r}\right)\left[\theta_{y} y_{t}+\phi_{\pi} \Delta \pi_{t}\right]+\varepsilon_{t}^{r}
$$

Parameter $\rho_{r}$ is used to capture the degree of interest rate smoothening, while $\theta_{y}$ and $\phi_{\pi}$ measures the responsiveness of the monetary agent to deviations in output and inflation, respectively.

\subsection{Fiscal Agent}

Following the study of Alege et al. (2019), the fiscal agent is modelled to follow a rule governed by expenditure and taxation represented as follows:

$$
T R_{t}+B_{t}=G_{t}+T P_{t}+B_{t-1}
$$

The left-hand side of the equation reflects the earnings of the government, where $T R_{t}$ denotes tax revenues received and $D_{t}$ represents earnings from issuing bonds. The right-hand side of the equation shows the expenditure of the government, where $G_{t}$ indicates government spending and $T P_{t}$ reflects transfer payments to households. Government spending is also assumed to follow an autoregressive process represented as:

$$
g_{t}=\rho_{g} g_{t-1}+\varepsilon_{t}^{g}
$$

\subsection{Market Clearing Conditions}

The aggregate output in the economy is based on the formal and informal output as well as investment and government expenditure. The aggregate resource constraint in the formal sector is defined as

$$
Y_{F, t}=C_{F, t}+I_{t}+G_{t}
$$

The aggregate resource constraint in the informal sector is represented as:

$$
Y_{I, t}=C_{I, t}
$$


Therefore, the overall economy constraint incorporating the formal and informal output is expressed as follows:

$$
Y_{t}=C_{F, t}+C_{I, t}+I_{t}+G_{t}
$$

\subsection{Exogenous Shocks Processes}

There are three exogenous shocks considered in the study, a monetary policy shock, government expenditure shock and formal firm productivity shock. All the shocks are defined based on an autoregressive form given as:

Monetary policy shock:

Government spending shock:

$$
r_{t}=\rho_{r} r_{t-1}+\varepsilon_{t}^{r}
$$

$$
g_{t}=\rho_{g} g_{t-1}+\varepsilon_{t}^{g}
$$

Formal productivity shock:

$$
a_{T, t}=\rho_{a_{T}} a_{T, t-1}+\varepsilon_{T, t}^{a}
$$

\subsection{Model Calibration}

The parameter values used in the model are derived based on existing studies in the DSGE literature with similar economic characteristics to Nigeria (Ahmed, et al., 2012; CBN, 2013; Lahcen, 2014; Oye, Alege and Olomola, 2018). Table 1 presents the summary of the parameter values.

Table 1. The NK-DSGE prior values of the parameters

\begin{tabular}{cllll}
\hline Symbol & Parameter Description & Distribution & Mean & Std.Dev \\
\hline$\sigma$ & Inverse elasticity of substitution & Normal & 3.00 & 1.00 \\
\hline$\varphi$ & Inverse elasticity of labour supply & Normal & 1.50 & 0.10 \\
\hline$\mu$ & $\begin{array}{l}\text { Elasticity of substitution between formal and informal } \\
\text { goods }\end{array}$ & Normal & 0.70 & 0.10 \\
\hline$\kappa$ & $\begin{array}{l}\text { Inverse elasticity of substitution between formal and } \\
\text { informal labour }\end{array}$ & Normal & 2.00 & 0.50 \\
\hline$\theta_{T}$ & Calvo price stickiness for formal firms & Beta & 0.75 & 0.05 \\
\hline$\rho_{a_{T}}$ & Productivity persistence for formal firms & Beta & 0.70 & 0.10 \\
\hline$\rho_{r}$ & Productivity persistence for interest rate & Beta & 0.70 & 0.10 \\
\hline$\rho_{t x}$ & Productivity persistence for government bond & Beta & 0.70 & 0.10 \\
\hline$\rho_{g}$ & Productivity persistence for government spending & Beta & 0.70 & 0.10 \\
\hline$\theta_{y}$ & Taylor rule weight on output & Gamma & 0.50 & 0.05 \\
\hline$\phi_{\pi}$ & Taylor rule weight on inflation & Gamma & 1.50 & 0.05 \\
\hline$\rho_{r}$ & Interest rate smoothening & Beta & 0.20 & 0.05 \\
\hline$\varepsilon_{t}^{a T}$ & Productivity shock for formal firms & Inverse Gamma & 0.10 & 2.00 \\
\hline$\varepsilon_{t}^{r *}$ & Productivity shock for interest rate & Inverse Gamma & 0.10 & 2.00 \\
\hline$\varepsilon_{t}^{r *}$ & Productivity shock for government spending & Inverse Gamma & 0.10 & 2.00 \\
\hline
\end{tabular}

Note: Std.Dev denotes standard deviation

\subsection{Data Source and Measurement}

The study makes use of quarterly data from 1991Q1 to 2018Q4. There are three observable variables in the DSGE model: real GDP (Y), informal GDP (YI) and inflation (PII). The data for Real GDP and inflation are both sourced from CBN Statistical bulletin and the informal GDP data is sourced from Dell'Anno and Adu (2020). 


\section{Empirical Analysis and Discussion of Findings}

\subsection{Model Diagnostics}

Several diagnostics tests are carried out in order to assess the empirical fit of the DSGE model to the Nigerian economy. In particular, the study makes use of four tests: the Blanchard-Khan stability condition; mode checks; multivariate convergence statistic; and examining the historical and smoothed variables.

\section{A. Blanchard-Khan Stability Condition}

The Blanchard-Khan stability condition is assessed towards establishing that the model has only one stable condition. The existence of one stable condition implies that in the advent of any disturbance, there is only one path to long term equilibrium. In essence, the model is not explosive. This unique solution is determined if and only if the number of unstable eigenvalues is equal to the number of non-predetermined variables. The Blanchard-Khan condition for the estimated NK-DSGE model of this study is satisfied as there are three eigenvalues greater than one in the modulus as there are also three forward-looking variables in the model.

B. Historical and Smoothed Variables

The examination of the graph of the historical and smoothed variables is done towards the assessment of whether measurement errors exist in the model. It is expected that the plot of the historical (actual) data and the smoothed data must be identical or overlap over each other. Figure 3 presents the plot of both variables and it can be seen that both variables overlap over each other. Hence, it can be concluded that the estimated model is free from measurement errors.
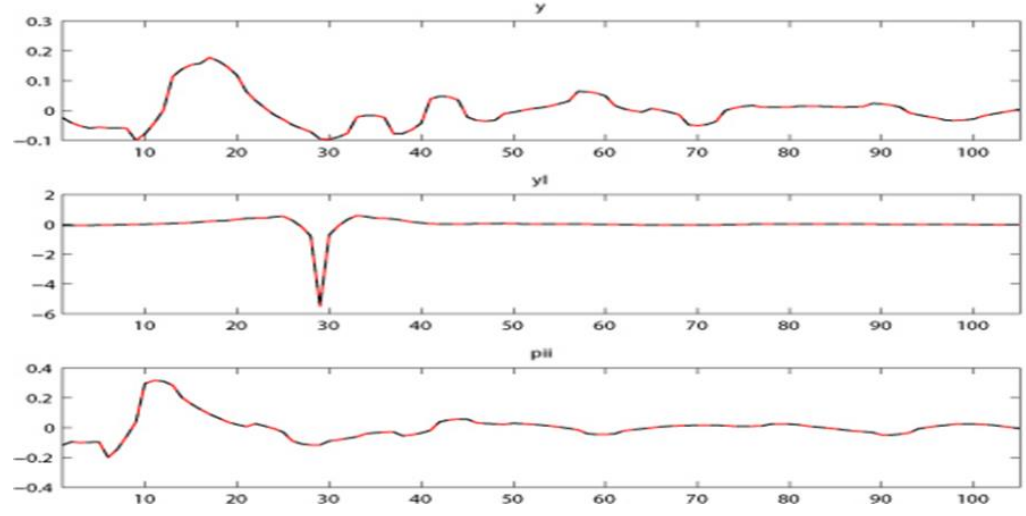

Figure 3. Plot of historical and smoothed variables

Source: Researcher's computation from MATLAB

\section{Mode Checks}

The mode check plots are examined towards ensuring that the Monte-Carlo optimisation technique used to estimate the posterior means are accurate. Ideally, it is expected that the maximum or the peak of the estimated mode, represented by the black line, should be closely located around the posterior likelihood vertical line, indicated by the blue line, for each parameter. Figure 4 shows that for each of the parameters of the model, the maximum point of estimated mode for each parameter lies closely around the posterior mode. 


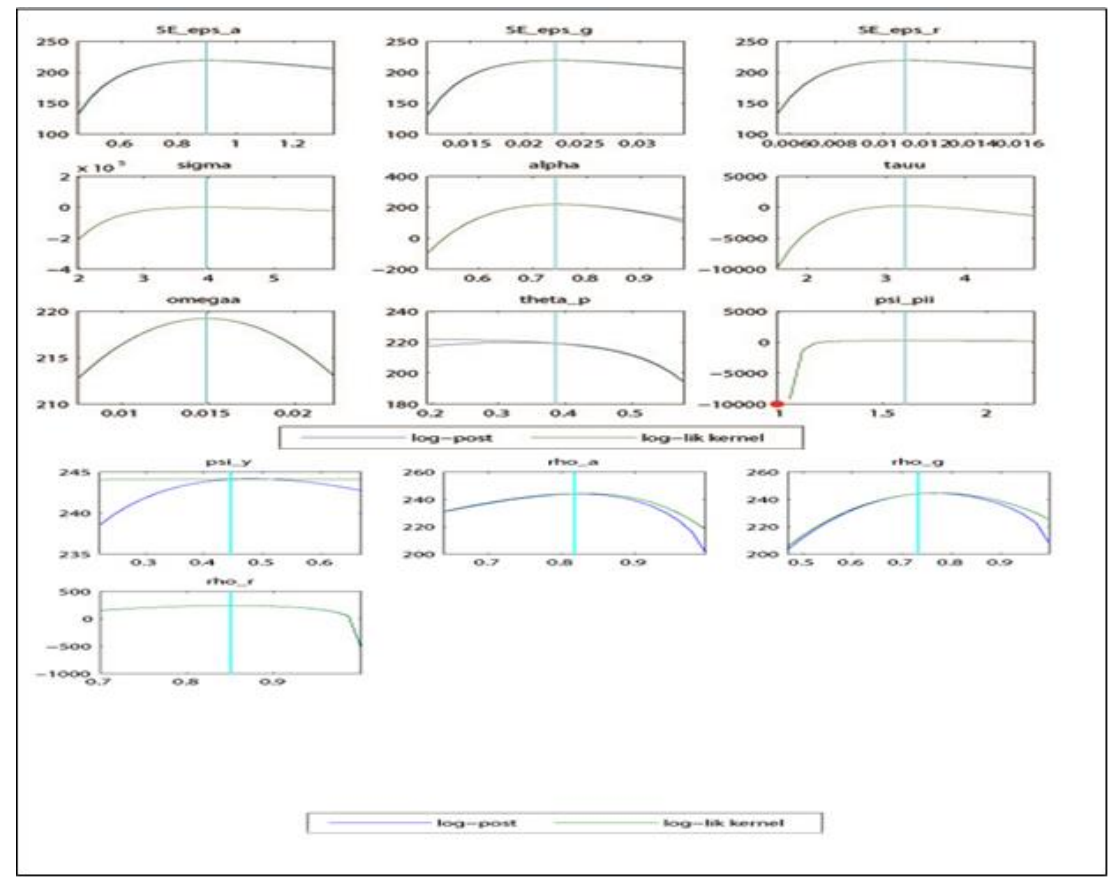

Figure 4. Mode check plots

Source: Researcher's computation from MATLAB

\section{Multivariate Convergence Statistics}

The multivariate convergence statistics is similar to the univariate convergence statistics in terms of interpretation, where both the red and blue lines are expected to be close to each other for convergence to be obtained. However, the major difference between the multivariate and univariate convergence statistics is that the former measures the overall convergence of the aggregate parameters in the model. The results are presented in Figure 5 and it depicts that to some extent both lines converge, hence it can be concluded that the estimated results in the study are valid.

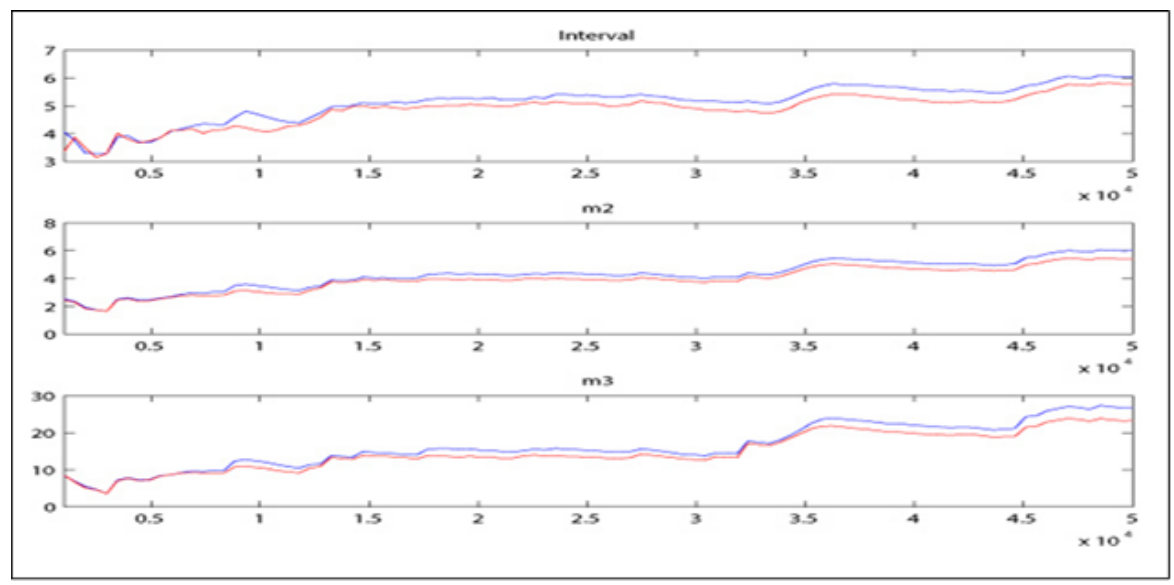

Figure 5. Multivariate convergence plot

Source: Researcher's computation from MATLAB 


\subsection{Bayesian Impulse Response Analysis}

\subsubsection{Impulse Response to Monetary Policy Shock}

The monetary policy shock is interpreted as a rise in the nominal interest rate, hence a contractionary policy intervention. The impact of the monetary policy shock on inflation is seen to be negative before it subsequently returns to its steady state within 5 quarters. This finding conforms to theoretical expectations that a rise in interest rate typically causes the price level of goods and services to trend downwards in the long run (Figure 6).

A positive shock to interest rate induces an initial decline in aggregate output. This finding is not surprising given that a rise in interest rates typically brings about a larger cost of borrowing for firms and can curtail expansion of production activities in the informal economy. Afterwards, it can be seen that the contractionary impact of the monetary policy shock on output begins to dwindle out and starts to rise, returning to its steady state.

In contrast, for informal output, a positive shock to interest rate brings about an increase in the level of informal output in the short-run. Kolev and Morales (2005) note that an explanation for this finding is because of the substitution effect of labour between the formal and informal firm. The rise in interest rate leading to higher cost of borrowing and fall in production in the formal sector induces a fall in employment levels. This then prompts a substitution of labour from formal sector to the informal economic, consequently leading to a rise in informal economic activities and output in the short-run. However, in the long-run, we notice the effect wears out which could be explained by the low level of price stickiness in the informal sector. Ahmed et al., (2012) obtained similar results for Pakistan.

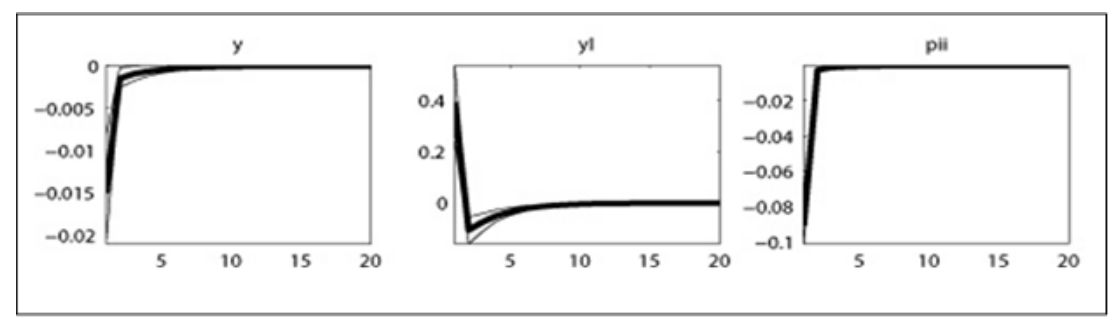

Figure 6. Impulse response to monetary policy shock

Source: Researcher's computation from MATLAB

\subsubsection{Impulse Response to Fiscal Policy Shock}

From Figure 7, a one percent standard deviation shock to fiscal policy, a rise in government expenditure, positively impacts total output. This finding is not surprising given that expansionary fiscal policies tends to stimulate output. The result also shows that a positive shock to government spending also leads to an increase in the price level of goods and services. This conforms with theoretical expectations as higher government spending causes output to rise, which leads to inflationary pressures on the economy. In terms of the effect of the fiscal policy shock on informal output, the result indicates that the initial impact is negative, although it weakens overtime and the economy returns to its long run steady state path after 5 quarters. The findings obtained here are similar to Lahcen (2014) and Ahmed et al., (2012) results obtained for Morocco and Pakistan.

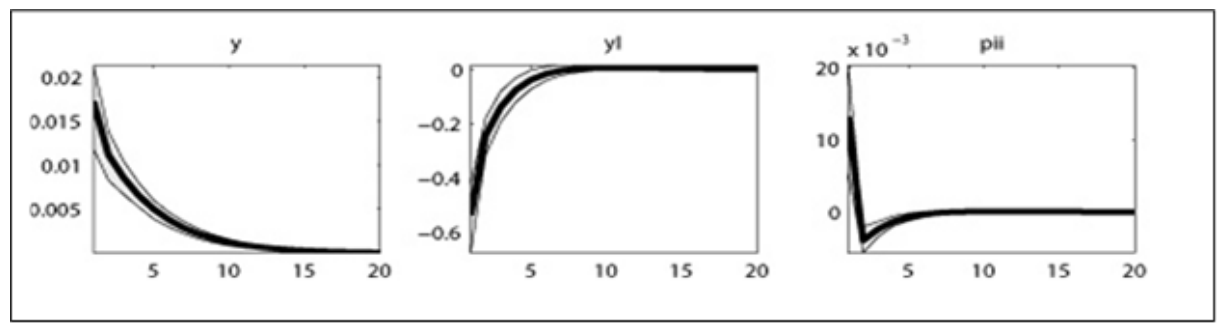

Figure 7. Impulse response to fiscal policy shock

Source: Researcher's computation from MATLAB 


\subsubsection{Impulse Response to Productivity Shock}

A one percent standard deviation shock to productivity in the tradable formal sector expectedly leads to an increase in the total output as seen in Figure 8, although the magnitude of the increase weakens after the fifth quarter. Also, the positive tradable formal productivity shock has a positive impact in the output in the informal sector, although smaller when compared to total output. This finding reflects the model characteristics as the productivity shock mostly affects the formal sector.

The findings obtained here are similar to Lahcen (2014) results obtained for Morocco. In particular, the findings from the study indicated that in the advent of a formal productivity shock triggered an increase in tradable output and consumption. Likewise, the impulse response analysis conducted by Ahmed et al, (2012) showed that productivity shocks tends to lead to an increase in the level of output in the formal and informal sector. The findings also provided evidence of a decline in the level of inflation.

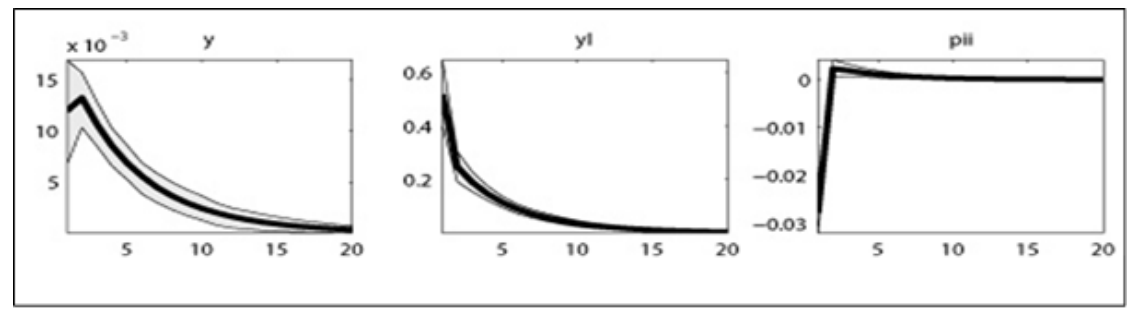

Figure 8. Impulse response to tradable formal productivity shock

Source: Researcher's computation from MATLAB

\subsection{Variance Decomposition}

The variance decomposition analysis is used to determine how much variation in the model is generated by an individual shock. The method helps to establish the relative importance of a shock as a source of volatility to a macroeconomic variable. Table 2 presents the variance decomposition of the observable variables in relation to the shocks. From the results presented, it can be seen that productivity shock and fiscal policy shocks account for the most variation in total output. Productivity shock accounts for about 35.38 percent, while the fiscal policy shock contributed about 47.63 percent. In contrast, the monetary policy shock accounted for the least variation in aggregate output, about 17 percent.

For informal output, similar results were obtained as both productivity shock and fiscal policy shocks contributed the largest to the variations, while monetary policy shock accounted for the least amount of variations. In particular, the productivity shock was responsible for about 33.86 percent of variations in informal output. Whereas, fiscal policy shock and monetary policy shock accounted for about 45.21 percent and 20.93 percent of variations in informal output. In relation to inflation, the results point out that monetary policy shocks are responsible for the most amount of variations (91.31 percent), while productivity and fiscal policy shocks combined contribute about 8.68 percent of variations in inflation.

Table 2. Variance decomposition (Percent)

\begin{tabular}{llll}
\hline & Productivity Shock & Fiscal Policy Shock & Monetary Policy Shock \\
\hline Total Output & 35.38 & 47.63 & 17.00 \\
\hline Informal Output & 33.86 & 45.21 & 20.93 \\
\hline Inflation & 6.30 & 2.38 & 91.31 \\
\hline
\end{tabular}

Source: Researcher's computation from MATLAB 


\section{Conclusion}

The central objective of this study was to investigate the impact of monetary and fiscal shocks are transmitted on macroeconomic aggregates, in particular, output and inflation, in the presence of an informal labour market. The study made use of the DSGE model and it was estimated using the Bayesian approach. The overall finding from the Bayesian Impulse response analysis indicated that in the advent of monetary policy shocks, the informal sector tends to react differently to the formal sector. In particular, we observe that while aggregate (formal) output was observed to decline as expected when nominal interest rose, on the other hand, there was a rise in informal output, in the short-run.

A possible explanation for this finding is the substitution effect of labour from the formal market to the informal market causing higher levels of economic activities in the informal sector. A key implication of the result for policymakers in Nigeria is that there is the need to formalise the informal sector in order to ensure the effectiveness of monetary policy. This is because, as seen from the results, both the formal and informal sector tends to react differently to monetary policy shocks. Hence, providing a form of dilemma for policymakers to either support the formal economy at the expense of the informal sector. Therefore, in order to strengthen the effectiveness of monetary policy, the government has to put in effort towards integrating the informal sector with the formal sector.

In conclusion, as a suggestion for further studies, the model presented can be extended to account for the role of external shocks and the rest of the world towards examining how the informal sector would react.

\section{Acknowledgements}

The researchers will like to thank Covenant University Centre for Research, Innovation and Discovery (CUCRID) for her financial support.

\section{References}

Ahmed, S., Ahmed, W., Pasha, F., Khan, S., \& Rehman, M. (2012). Pakistan economy DSGE model with informality. Working Paper No. 47. Research Department. State Bank of Pakistan.

Ahmed, W., Khan, S., \& Rehman, M. (2013). Optimal monetary policy in the presence of an informal sector and firm-level credit constraints. Research Department. State Bank of Pakistan.

Alege, P. O. (2012). A Business cycle model for Nigeria. CBN Journal of Applied Statistics, 3(1), 85-115.

Bandaogo, M. S. (2016). Fiscal and monetary policy in the presence of informality and the incentive to join a currency union. Retrieved from https://econ.washington.edu/file/2692/download?token=MBfs_6ZK

Calvo, G. (1983). Staggered prices in a utility-maximising framework. Journal of Monetary Economics, 12, 383-398.

Castillo, P., \& Montoro, C. (2010). Monetary policy in the presence of informal labour markets. Serie de Documentos de Trabajo Working Paper series. Banco Central de Reserva del Perú.

CBN. (2013). Dynamic Stochastic General Equilibrium (DSGE) model for monetary policy analysis in Nigeria. Abuja: Research Department, Central Bank of Nigeria.

CBN. (2017). Central Bank of Nigeria Statistical Bulletin. Abuja: CBN.

Dell'Anno, R., \& Adu, O. (2020). The size of the informal economy in Nigeria: a structural equation approach. International Journal of Social Economics.

Dixit, A. K., \& Stiglitz, J. E. (1977). Monopolistic competition and optimum product diversity. American Economic Review, 67(3), 297-308.

Junior, C., Garcia-Cintado, A., \& Usabiaga, C. (2017). Fiscal adjustments and the shadow economy in an emerging market. International Conference on Regional Science (pp. 1-36). Louvain-la-Neuve: The Home of Regional Science in Europe.

Kolev, A., \& Morales, J. (2005). Monetary Policy and the Informal Sector. Department of Economic History, University of Barcelona. Working Paper no. 75, pp. 1-34.

Lahcen, M. A. (2014). DSGE models for developing economies: an application to Morocco. MPRA Paper No. 6340. pp. 1-84.

Munkacsi, Z., \& Saxegaard, M. (2017). Structural reform packages, sequencing, and the informal economy. Washington: International Monetary Fund. 
National Bureau of Statistics (NBS). (2016). Formal and informal sector split of gross domestic product. Abuja: National Bureau of Statistics.

Oye, Q.-E., Alege, P., \& Olomola, P. (2018). Explicit fiscal and monetary policy interactions in a small open economy. 31st International Business Information Management (IBIMA) Conference (pp. 1-13). Milan.

Restrepo-Echavarria, P. (2014). Macroeconomic volatility: the role of the informal economy. European Economic Review, 70, 454-469.

SMEDAN, \& NBS. (2019). SMEDAN and national bureau of statistics collaborative survey: selected findings. Abuja: Small and Medium Enterprises Development Agency of Nigeria.

Taylor, J. B. (1993). Discretion Versus Policy Rules in Practice. Carnegie-Rochester Conference Series on Public Policy, 39, 195-214.

\section{Copyrights}

Copyright for this article is retained by the author(s), with first publication rights granted to the journal.

This is an open-access article distributed under the terms and conditions of the Creative Commons Attribution license (http://creativecommons.org/licenses/by/4.0/). 